\title{
Grid Photocoagulation Improves Reading Ability in Diffuse Diabetic Macular Oedema
}

\author{
E I MCNAUGHT, ${ }^{*}$ W S FOULDS $†$ and D ALLAN \\ Carluke and Glasgow
}

\begin{abstract}
Summary
Forty-eight patients with diffuse diabetic macular oedema were treated with perifoveal blue/ green Argon 'grid' laser photocoagulation. Clinical assessment of patients was supported by serial fluorescein angiography. Patients were followed up for one year after treatment, and a two year follow-up was obtained in 29 patients. Statistical analysis showed no significant improvement in distance acuity, but demonstrated clear benefit as regards reading ability.
\end{abstract}

This paper reports the results of a prospective trial of 'grid' photocoagulation for diffuse diabetic macular oedema carried out over a two year period.

Photocoagulation of focal areas of leakage in eyes with diabetic maculopathy has been reported as beneficial. ${ }^{1,2}$ Retrospective studies of indirect photocoagulation have shown resorption of oedema but little effect on visual acuity. ${ }^{1,3-8}$ Diffuse macular oedema carries a poor prognosis for vision and one of the main complaints of patients suffering from diffuse macular oedema is poor reading vision. Previous reports of focal or indirect photocoagulation for diabetic maculopathy have concentrated on changes in distance acuity. None has investigated the effects of such treatment on reading vision.

\section{Selection of Patients}

Diabetic patients with macular oedema attending out-patient clinics in the West of Scotland were referred, for possible inclusion in the trial, to a special clinic set up by one of us $(\mathrm{EMcN})$. There was no age restriction and patients selected ranged in age from 38 to 76 years (mean 59 years median 58 years). To be included in the trial reading vision in one eye had to be N6 or less and macular oedema alone judged to be the cause of the visual loss. All patients underwent ophthalmoscopy, refraction, contact lens biomicroscopy and fluorescein angiography. Patients selected for the trial had diffuse macular oedema as demonstrated by clincial examination and by fluorescein angiography. Fluorescein angiography was carried out with the early frames usually concentrated on the poorer eye and delayed frames (Fig 1) recorded from each eye. In cases where both eyes had macular oedema, and in whom the difference in corrected near vision between the two eyes was small, a second angiogram was taken with the early frames recorded from the other eye.

Forty-eight patients were identified as suit-

From ${ }^{*}$ Law Hospital, Carluke Lanarkshire. †Tennent Institute of Ophthalmology, University of Glasgow, Western Infirmary, Glasgow and West of Scotland Health Boards', Department of Clinical Physics and BioEngineering, Glasgow.

Correspondence to: Dr. E I McNaught, Department of Ophthalmology, Law Hospital, Carluke, Lanarkshire, Scotland ML8 5ER

Presented at a meeting of the Scottish ophthalmological Club and The Netherlands Ophthalmological Society 3 and 4 October 1986. 


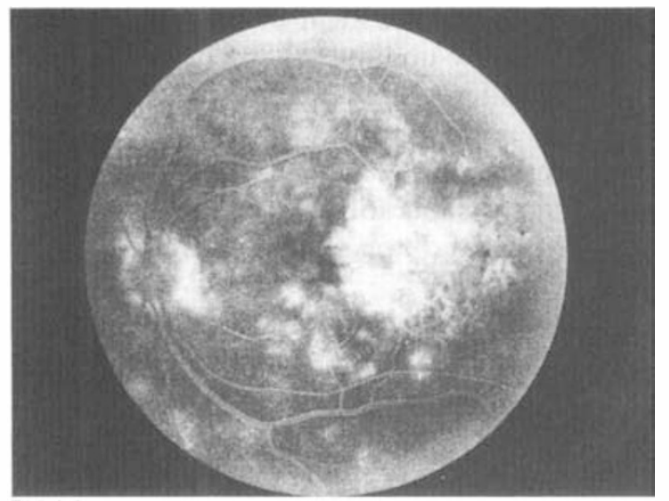

Fig. 1. Fluorescein angiogram (late phase 310 secs). Diffuse diabetic macular oedema.

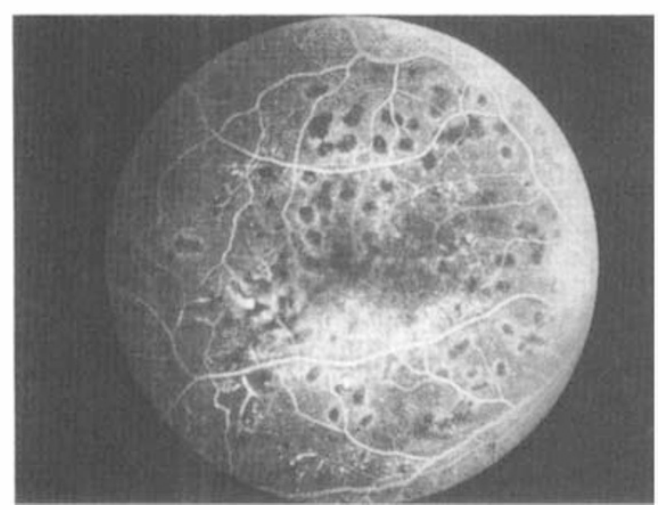

Fig. 2. Fluorescein angiogram to illustrate the pattern of laser photocoagulation used in the treatment of diffuse diabetic macular oedema.

able for inclusion in the trial. Corrected distance acuity (Snellen acuity) and near vision (Faculty of Ophthalmologists near vision test type) were tested under standard conditions of illumination. Reading vision was recorded with the test type held at 8 inches and an appropriate reading correction was used (+3.50 DS maximum addition to distance correction).

In some patients static perimetric profiles measured at $180^{\circ}$ on the Oculus Tubinger Perimeter were carried out.

\section{Selection of eye to be Treated}

Where one eye had $\mathrm{N} 5$ reading vision or better and the other N6 or worse the poorer eye was selected for treatment (22 cases). Where the two eyes were affected equally $( \pm 1$ step on the near vision chart) one eye chosen at random was treated (8 cases). The remaining eyes were affected unequally ( 2 steps or greater difference on the near vision chart) and while usually the better eye was treated (13 cases) initially a few patients in this category had the poorer eye treated ( 5 cases).

\section{Treatment Schedule}

The selected eye was treated with a grid of 50 to 100 , blue/green Argon photocoagulation applications of $100 \mu \mathrm{m}$ spot size applied through a standard Goldmann 3-mirror contact lens. The lesions were distributed within the major vascular arcades avoiding the avascular zone. The aim was to produce a lesion just visible to the operator and this was usually achieved with an energy level of 0.5 to $0.75 \mathrm{~W}$ for $0.2 \mathrm{~s}$ duration. The pattern used is illustrated in Figure 2.

\section{Follow-up}

Patients were, as far as possible, re-examined at 1 week, 1 month, 3 months, 6 months, 1 year and 2 years after treatment. On these occasions best corrected distance and near visions were recorded. Fluorescein angiography was repeated 1 month and 6 months after treatment. Follow-up was incomplete in 2 cases who died 4 and 6 months respectively after treatment.

\section{Statistical Methods and Analysis of Results}

Changes in distance acuity and near vision were expressed in arbitrary unit values. For distance vision each line of difference on the Snellen chart was regarded as one unit so that for example a change in acuity from $6 / 36$ to $6 / 9$ was expressed as +4 units $(6 / 36-6 / 24-$ $6 / 18$ - 6/12 - 6/9). For acuities below $6 / 60$ the following values denoted unit steps: $5 / 60$, 4/60, 3/60, 2/60, 1/60, CF, HM.

Changes in near vision were recorded in units using the $\mathrm{N}$ values (N4.5, N5, N6, etc) as unit steps. The unit steps of visual acuity are of course of unequal size and for this reason non-parametric tests were used in the statistical analysis to take account of the ordinal nature of the visual acuity data.

\section{Results}

It was important to determine at the outset whether the distance and near acuity of 
treated and untreated eyes were comparable initially. A comparison of the two groups showed that the mean distance acuity in the two groups was similar at $6 / 24$ and although the range of acuities among the untreated eyes was greater than among those treated there was no statistically significant difference $(0.2<p<0.5)$ (Mann-Whitney). Similarly although the mean near vision for the untreated group was $\mathrm{N} 10$ and for the treated N12 the difference was not significant $(0.1<\mathrm{p}<0.2)$ (Mann-Whitney).

As the initial acuity might have influenced the subsequent behaviour of the eye the changes in both near and distance vision occurring in the untreated eyes were examined. Overall there was a tendency towards deterioration in the untreated eyes. Changes in near and distance vision were studied separately. For near vision the behaviour of untreated eyes initially seeing $\mathrm{N} 8$ or better was compared with that of those seeing N10 or worse. For distance vision the groupings were $6 / 12$ or better and $6 / 18$ or worse. These divisions split the patients as equally as possible. In either case the changes in acuity from the initial values were compared at each follow-up time. Changes for individual eyes ranged up to 6 units of improvement or deterioration. Statistical comparisons of near and distance vision made with the Mann-Whitney test demonstrated that both groups of eyes behaved similarly with no significant differences between groups being demonstrated at any of the follow-up times studied ( $P \geqslant 0.56$ for distance vision at all times; $P \geqslant 0.18$ for near vision at all follow-up times).

In summary, the natural progression of the untreated condition is for slight deterioration of vision, and is similar whether an eye has an initially good or poor vision. This coupled with the modest difference between initial acuities of treated and untreated eyes, indicates that the untreated eyes can be used with validity as a reference against which to measure the results of the photocoagulation treatment.

\section{Near Vision}

The behaviour of treated and untreated eyes was compared in five comparisons using three separate statistical methods at each of the five follow-up times.

(1) - Significance of changes in near vision in untreated eyes (by two-tailed sign test) (Table I).

(2) - Significance of changes in near vision in treated eyes (by two-tailed sign test) (Table II)

(3) - Significance of difference between changes in treated and untreated eyes in an unpaired comparison, ie, treated group compared with untreated group (by Mann-Whitney test) (Table III).

(4) - Significance of mean changes in near vision in arbitrary units of treated eyes compared with fellow untreated eyes in a paired comparison, ie, positive differences in favour of treated eyes being tested for a significance difference from zero which would indicate no benefit from treatment (Wilcoxon signed-rank test) (Table IV).

(5) - Significance of difference between changes in treated and untreated eyes in a paired comparison, ie, each eye compared with its fellow (by two-tailed sign test) (Table V).

The principal results are set out in Tables I-VI. Firstly the untreated eyes and treated eyes were divided into 3 categories - better, same or worse at each follow-up time irrespective of the magnitude of the changes. Looking at untreated eyes (Table I) it can be seen that although there is a tendency for more eyes to be worse and fewer unchanged at longer follow-up times the differences were not significant at any follow-up time up to two years $(\mathrm{P}=>0.2$ at all follow-up times). For treated eyes however, there were significant improvements at follow-up times up to and including 6 months (Table II).

An unpaired comparison between the near vision of treated eyes and the baseline set by the untreated eyes (Table III) revealed significant benefits in near vision in treated eyes at all follow-up times to 1 year. Even at 2 years, the difference in favour of the treated eyes just failed to reach statistical significance. It is worth noting that for treated eyes the results at all follow-up times had a positive value indicating improvement while for untreated eyes the results were approxi- 
Table I Diffuse Diabetic Maculopathy. Changes in near vision in untreated eyes at various follow-up times.

\begin{tabular}{lcrrrc}
\hline $\begin{array}{l}\text { Follow-up } \\
\text { Time }\end{array}$ & Total No & Better & Same & Worse & $\begin{array}{c}\text { Significance* } \\
\text { Level }\end{array}$ \\
\hline 1 month & 44 & $5(11 \%)$ & $37(84 \%)$ & $2(5 \%)$ & NS \\
3 months & 44 & $6(14 \%)$ & $29(66 \%)$ & $9(20 \%)$ & NS \\
6 months & 35 & $6(17 \% ;$ & $23(66 \%)$ & $6(17 \%)$ & NS \\
1 year & 29 & $3(10 \%)$ & $18(62 \%)$ & $8(28 \%)$ & NS \\
2 years & 17 & $3(18 \%)$ & $8(47 \%)$ & $6(35 \%)$ & NS \\
\hline
\end{tabular}

*two-tailed sign test

Table II Diffuse Diabetic Maculopathy. Changes in near vision in treated eyes at various follow-up times.

\begin{tabular}{lccccc}
\hline $\begin{array}{l}\text { Follow-up } \\
\text { Time }\end{array}$ & Total No & Better & Same & Worse & $\begin{array}{c}\text { Significance* } \\
\text { Level }(P=)\end{array}$ \\
\hline 1 month & 44 & $34(77 \%)$ & $6(14 \%)$ & $4(9 \%)$ & $<0.001$ \\
3 months & 46 & $35(76 \%)$ & $5(11 \%)$ & $6(13 \%)$ & $<0.001$ \\
6 months & 37 & $27(72 \%)$ & $5(14 \%)$ & $5(14 \%)$ & $<0.001$ \\
1 year & 30 & $17(57 \%)$ & $6(20 \%)$ & $7(23 \%)$ & NS \\
2 years & 18 & $11(61 \%)$ & $2(11 \%)$ & $5(28 \%)$ & NS \\
\hline
\end{tabular}

${ }^{*}$ two-tailed sign test

Table III Diffuse Diabetic Maculopathy. Comparison of mean changes in near vision (in arbitrary units see text) for treated and untreated eyes at various follow-up times

\begin{tabular}{|c|c|c|c|c|c|}
\hline \multirow[b]{2}{*}{$\begin{array}{l}\text { Follow-up } \\
\text { Times }\end{array}$} & \multicolumn{2}{|c|}{ Treated } & \multicolumn{2}{|c|}{ Untreated } & \multirow[b]{2}{*}{$\begin{array}{l}\text { Significance* } \\
\text { Level }(P=)\end{array}$} \\
\hline & $\begin{array}{l}\text { No of } \\
\text { eyes }\end{array}$ & $\begin{array}{c}\text { Mean } \\
\text { change in } \\
\text { near vision }\end{array}$ & $\begin{array}{l}\text { No of } \\
\text { Eyes }\end{array}$ & $\begin{array}{c}\text { Mean } \\
\text { change in } \\
\text { near vision }\end{array}$ & \\
\hline 1 month & 44 & +1.6 & 44 & +0.2 & $<0.001$ \\
\hline 3 months & 46 & +1.4 & 44 & -0.1 & $<0.001$ \\
\hline 6 months & 37 & +1.1 & 35 & +0.1 & $<0.001$ \\
\hline 1 year & 30 & +0.6 & 29 & -0.2 & $<0.01$ \\
\hline 2 years & 18 & +0.4 & 17 & -0.5 & NS \\
\hline
\end{tabular}

*Mann-Whitney test

mately zero for follow-up times to 1 year indicating no change while at 2 years a trend towards deterioration was indicated by a negative value.

When a comparison was made between treated and untreated eyes, pairing each treated eye with its fellow (Table IV), similar results were obtained. The mean difference in arbitrary units between the near vision of treated as compared with fellow untreated eyes had a positive value at all follow-up times to 2 years although the difference between treated and untreated eyes reached statistical significance for the first 4 follow-up periods to 1 year probably because the total numbers having a 2-year follow-up were fairly small. A similar paired comparison between treated and fellow untreated eyes based upon the numbers better, the same or worse is shown in Table $\mathrm{V}$. Once again it is apparent that a significantly greater number of treated eyes were better than the 
Table IV Diffuse Diabetic Maculopathy. Comparison of mean changes in near vision (in arbitrary units) or treated eyes compared with fellow untreated eyes

\begin{tabular}{lccc}
\hline $\begin{array}{l}\text { Follow-up } \\
\text { Time }\end{array}$ & $\begin{array}{c}\text { Noof } \\
\text { Patients }\end{array}$ & $\begin{array}{c}\text { Mean difference between } \\
\text { treated \& untreated eyes }\end{array}$ & $\begin{array}{c}\text { Significance Level* } \\
\text { Sign test }(P=)\end{array}$ \\
\hline 1 month & 44 & +1.4 & $<0.001$ \\
3 months & 44 & +1.4 & $<0.001$ \\
6 months & 35 & +1.1 & $<0.01$ \\
1 year & 29 & +0.8 & $<0.05$ \\
2 years & 17 & +0.9 & $\mathrm{NS}$ \\
\hline
\end{tabular}

(+ values indicate that treated eyes are better than untreated eyes)

${ }^{*}$ Wilcoxon signed rank test

Table V Diffuse Diabetic Maculopathy. Comparison between treated and fellow untreated eyes in relation to whether near vision of treated eyes was better, worse or the same as untreated eyes

\begin{tabular}{lccccc}
\hline $\begin{array}{l}\text { Follow-up } \\
\text { Time }\end{array}$ & $\begin{array}{c}\text { No of } \\
\text { Patients }\end{array}$ & Better & Same & Worse & $\begin{array}{c}\text { Significance* } \\
\text { Level }(P=)\end{array}$ \\
\hline 1 month & 44 & $33(75 \%)$ & $5(11 \%)$ & $6(17 \%)$ & $<0.001$ \\
3 months & 44 & $33(75 \%)$ & $3(7 \%)$ & $8(18 \%)$ & $<0.001$ \\
6 months & 35 & $25(71 \%)$ & $3(9 \%)$ & $7(20 \%)$ & $<0.01$ \\
1 year & 29 & $17(58 \%)$ & $6(21 \%)$ & $6(21 \%)$ & $<0.05$ \\
2 years & 17 & $10(59 \%)$ & $4(24 \%)$ & $3(17 \%)$ & NS \\
\hline
\end{tabular}

*two-tailed sign test

Table VI Comparison of near vision in three sub-groups of eyes selected by initial level of near vision and assessed by Mann Whitney Test

\section{Initial Acuity}

\begin{tabular}{lccccccccccccc} 
& \multicolumn{9}{c}{ N8 or better } & \multicolumn{3}{c}{ N12 or better } & \multicolumn{9}{c}{ N14 or worse } \\
Follow-up & $T$ & $U$ & Diff & $P=*$ & $T$ & $U$ & Diff & $P=*$ & $T$ & $U$ & Diff & $P=*$ \\
\hline 1 month & 17 & 22 & +1.0 & $<0.001$ & 30 & 27 & +1.2 & $<0.001$ & 14 & 17 & +2.0 & +0.02 \\
3 months & 17 & 22 & +0.7 & $<0.01$ & 31 & 28 & +1.1 & $<0.001$ & 15 & 16 & +2.2 & $<0.001$ \\
6 months & 15 & 20 & +0.6 & $<0.01$ & 25 & 24 & +1.1 & $<0.001$ & 12 & 11 & +0.9 & NS \\
1 year & 13 & 19 & +0.3 & NS & 21 & 23 & +0.9 & $<0.01$ & 9 & 6 & +0.3 & NS \\
2 years & 7 & 13 & -0.8 & NS & 13 & 15 & +1.0 & NS & 5 & 2 & +0.4 & NS \\
\hline
\end{tabular}

*Mann-Whitney test

Differences between near vision (Diff) for treated (T) and untreated (U) eyes are expressed in arbitrary units

Significance levels $(\mathrm{P}=)$ are indicated

untreated eyes at all follow-up times to 2 years although statistical significance was only achieved for follow-up times to 1 year. Approximately 20 per cent of treated eyes were worse than untreated eyes at all followup times while the majority of treated eyes (59-75 per cent) were better than the untreated eyes.
As there was a possibility that grid coagulation in eyes with good vision might adversely affect near vision the results of treatment of eyes with an acuity of N8 or better (17 patients) was looked at. Significant improvement in near vision up to and including 6 months, was noted (Table VI).

To see if the initial level of near acuity 
influenced the outcome of treatment another grouping of cases was made. Treated and untreated eyes seeing N12 or better initially were compared. There was a significant gain in vision for the treated group at up to 1 year (Table VI). On the other hand a similar comparison between treated and untreated eyes all initially seeing N14 or worse (Table VI) showed relative improvements for the treated eyes to be restricted to the 1 month and 3 month follow-up times. Plainly after 2 years the numbers remaining in this latter grouping are too few for the analysis to be meaningful.

It is interesting to note from Figure 3 that at 6 months after photocoagulation, 72 per cent of treated eyes showed improvement in vision, 14 per cent were unchanged and 14 per cent were worse. For untreated eyes 17 per cent were improved, 66 per cent unchanged and 17 per cent worse.

\section{Distance Acuity}

The distance acuities of treated and untreated eyes were subjected to the same statistical analyses as the near vision figures. No significant beneficial effect on distance acuity resulted from grid photocoagulation at any of the time intervals studied or for any of the sub-groups of patients analysed, although there was a trend towards slower deterioration in treated than untreated eyes.

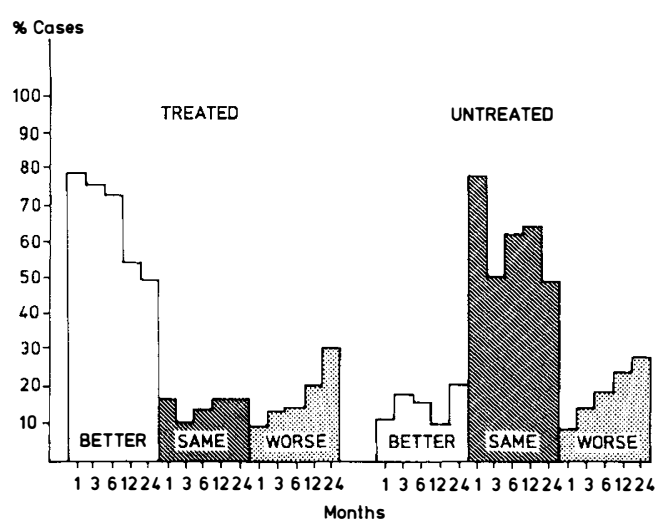

Fig. 3. Histogram showing percentages of treated or untreated patients whose near vision improved, was no different, or deteriorated at various followup intervals.

\section{Discussion}

Recently published studies have shown that grid photocoagulation has a beneficial effect as regards clearing of macular oedema but a very doubtful and sometimes deleterious effect on visual acuity. The present study has confirmed that grid photocoagulation avoiding the avascular zone has no significant beneficlal effect on distance visual acuity. It did however result in the clearing of macular oedema and a significant improvement in reading vision for periods up to one year. At first sight the results appear paradoxical; but reading ability requires not only visual acuity but parafoveal vision in addition, and it seems likely that although foveal vision did not recover significantly when macular oedema absorbed, parafoveal vision did, thus allowing scanning ability and consequent improvement in reading facility. In some reported studies macular photocoagulation has been brought very close to the fovea and many patients so treated have complained of persistent paracentral scotomas..$^{8,9}$ This was not the case in the present study where the grid coagulation did not encroach on the avascular zone. The recovery of function in the parafoveal area of the visual field was confirmed in some cases by an improvement in the static perimetric profile close to fixation (Fig 4) and in some instances where colour vision had been tested, by an improvement in the Farnsworth Munsell 100 Hue score (Fig 5).

In this study several points of clinical interest emerged. In two cases when macular oedema improved after treatment, but later recurred, laser grid coagulation applied for a second time again produced improvement. In the first of these, where initial near vision was N12, a three step improvement in near vision to N6 following grid photocoagulation was maintained for 3 months, but this had fallen to N10 at one year. Repeat macular grid photocoagulation produced one more step of improvement giving N8 vision which was maintained for a further year. In the second case a two step improvement in near vision (N6 to N4.5) at 3 months had reverted to N6 by one year. Thereafter a second application of macular grid photocoagulation produced one step improvement in near vision to 
N5 which was maintained for a further 18 months.

Immediately after photocoagulation patients often experienced a temporary worsening of vision associated with an increase in macular oedema. McDonald and Schatz reported similar findings in $1985 .{ }^{9}$ Following this temporary worsening of vision oedema was noted to clear in the majority of cases with a subjective improvement in vision. In cases where near vision was worse one week after treatment it had usually improved by one month after treatment. In only 3 patients was near vision poorer than pre-treatment levels after one month. By 3 months only one case had near vision less good than the pretreatment level. In this latter case deterioration from N14 to N36 was recorded after grid coagulation and the situation was not improved by applying a further grid. Eight months later however, disc new vessels developed and panretinal ablation was carried out. Shortly thereafter near vision improved from N36 to N18. Improved near vision was noted in 2 further patients in whom panretinal ablation became necessary because of proliferative retinopathy. In the first of these near vision had improved from N10 to N6 following macular grid coagulation and further improved to $\mathrm{N} 5$ after panretinal ablation. The second patient improved from $\mathrm{N} 8$ to N4.5 after grid photocoagulation and maintained this vision for 6 months. Near vision then fell from $\mathrm{N} 4.5$ to $\mathrm{N} 12$ as the need for panretinal ablation became evident. Following panretinal ablation near vision recovered to $\mathrm{N} 4.5$ - the level originally achieved after grid coagulation.

It is well known that photocoagulation damages the posterior blood ocular barrier $^{10-13}$ and an increase in macular oedema immediately post-laser was not unexpected. Laser photocoagulation in the macular area is a destructive form of therapy and the amount of coagulation required to produce visual benefit without significant paracentral scotoma has still to be determined.

The mechanisms by which laser grid photocoagulation may produce a beneficial effect on macular oedema remain conjectural.
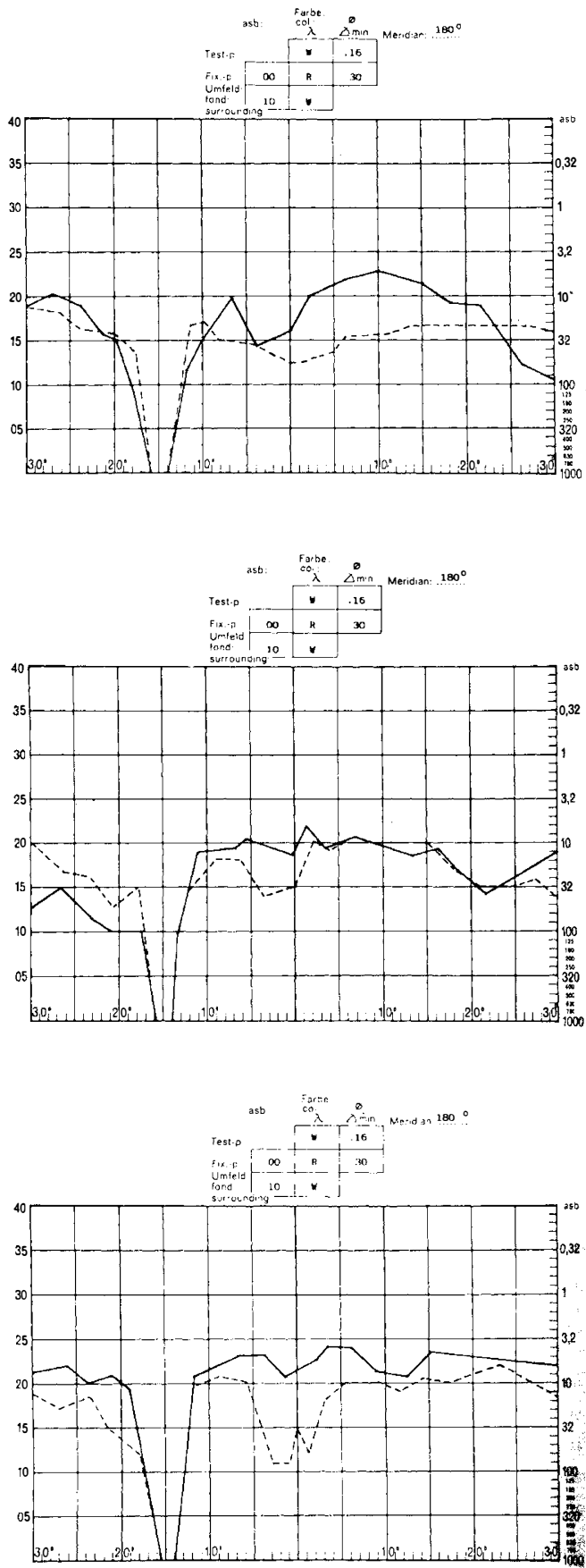

Fig. 4. Diffuse diabetic macular oedema; 3 exam ples $(a, b, c)$ of the static perimetric profiles before treatment (--) and 3 months after treatment (with grid photocoagulation. There is a significar improvement in central sensitivity although foved. sensitivity remains depressed. 

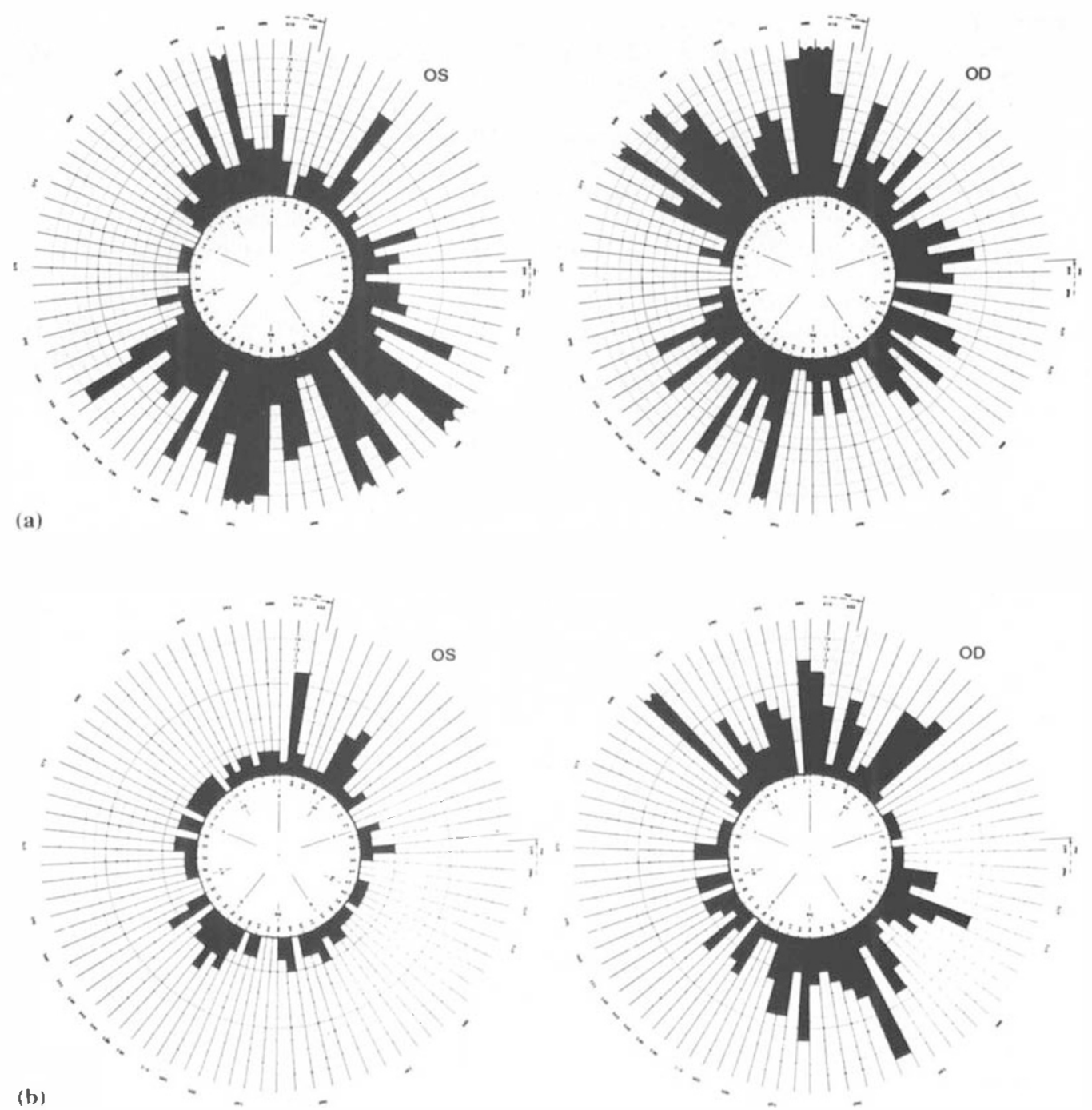

Fig. 5. Diffuse diabetic macular oedema; Farnsworth Munsell 100 Hue Test before treatment (a) and 6 months after treatment of left eye $(b)$. The treated eye shows a significant improvement in colour vision (same patient as Fig 4c).

\section{Conclusions}

The treatment described appears to have clear benefit as regards near vision and reading ability when this is reduced by diffuse diabetic maculopathy. No significant improvement in distance acuity results from the treatment. Benefits of treatment are most marked during the first year after treatment and the results appear better for eyes with a near vision of N12 or better before treatment.

It is a pleasure to record thanks to clinicians who referred cases. We should like to thank Miss E McClure, Principal Optician, Tennent Institute of Ophthalmology and Mrs A Currie of the Technical Staff of the Tennent Institute of Ophthalmology. 


\section{References}

1 Blankenship G W. Diabetic macular oedema and laser photocoagulation. Ophthalmology 1979. 86: 69-75.

${ }^{2}$ British Multicentre Study Group. Photocoagulation for Diabetic Maculopathy. A randomised controlled trial using Xenon Arc. Diabetes 1983. 32: 1011.

${ }^{3}$ Patz R, Schatz H, Berkow J W et al. Macular Oedema. An overlooked complication of diabetic retinopathy. Ophthalmology 1973. 77: 34-42.

4 Townsend C, Bailey J, Kohner E. Xenon Arc photocoagulation for the treatment of diabetic maculopathy interim report of a multicentre controlled clinical study. $\mathrm{Br} \mathrm{J}$ Ophthalmol 1980. 64: 385-91.

${ }^{5}$ Bresnick G H. Diabetic Maculopathy; a critical review highlighting diffuse macular edema. Ophthalmology 1983. 90: 1301-17.

6 Early Treatment Diabetic Retinopathy Study Report No 1. Arch Ophthalmol 1985. 103. 1796-1806.

7 Bresnick G H. Diabetic Macular Oedema. Ophthalmology 1986. 93: 989-97.
${ }^{8}$ Olk R J. Modified grid Argon (blue/green) laser photocoagulation for diffuse diabetic macular edema. Ophthalmology 1986. 93: 945.

${ }^{9}$ McDonald H C and Schatz H. Grid photocoagulation for diffuse macular oedema. Retina 1985. 5: 65-71.

10 Peyman G A, Spitznas M, Straatsma B R. Peroxidase diffusion in the normal and photocoagulated retina. Invest Ophthalmol 1971. 10: 181-9.

${ }^{11}$ McNaught E I, Foulds W S, Johnson N F. The effect of photocoagulation on the barrier function of the pigment epithelium. Proc 4th Wm Mackenzie Symposium. Trans Ophthalmol Soc UK 1977. 97: 634-40.

12 Johnson N F, McNaught E I, Foulds W S. The effects of photocoagulation on the barrier function of the pigment epithelium. Proc 4th Wm Mackenzie Symposium. Trans Ophthalmol Soc UK 1977. 97: 640-51.

${ }^{13}$ Foulds W S. The clinical significance of transscleral fluid transfer. Trans Ophthalmol Soc $U K$ 1976. 96: 290-308. 